\title{
Research Paper: Electromyography-based Fatigue Assessment During Endurance Testing by Different Vibration Training Protocols
}

\author{
Mohd Mukhtar Alam ${ }^{1}$ (D), Abid Ali Khan ${ }^{2 *}$ (D)
}

1. Department of Mechanical Engineering, Vivekananda Global University, Jaipur, Rajasthan, India.

2. Ergonomics Research Division, Department of Mechanical Engineering, ZHCET, Faculty of Engineering \& Technology, Aligarh Muslim University, Aligarh, Uttar Pradesh, India.

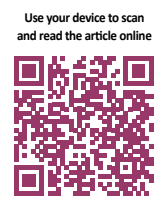

ditation: Mukhtar Alam M, Ali Khan A. Electromyography-based Fatigue Assessment During Endurance Testing by Different Vibration Training Protocols. Iranian Rehabilitation Journal. 2021; 19(1):85-98. http://dx.doi.org/10.32598/irj.19.1.1150.1

doi'http://dx.doi.org/10.32598/irj.19.1.1150.1

Article info:

Received: 04 Jun 2020

Accepted: 30 Mar 2021

Available Online: 01 Mar 2021

Keywords:

Vibration therapy,

Muscle fatigue, Surface

electromyography, Endurance

training

\section{A B S T RACT}

Objectives: This study presents a method of assessing muscle fatigue during endurance testing at 50\% maximal voluntary contraction (MVC) using electromyography (EMG) information as indirect indices of fatigability in the forearm muscles, namely, flexor digitorum superficialis (FDS); flexor carpi ulnaris (FCU); extensor carpi ulnaris (ECU) and extensor carpi radialis brevis (ECRB)." This study presents a method of assessing muscle fatigue during endurance testing at $50 \%$ maximal voluntary contraction (MVC) using electromyography (EMG) information as indirect indices of fatigability in the forearm muscles, namely, flexor digitorum superficialis (FDS); flexor carpi ulnaris (FCU); extensor carpi ulnaris (ECU) and extensor carpi radialis brevis (ECRB).

Methods: A randomized comparative experimental design was used during endurance test with 8 VT protocols; based on different combinations of vibration frequency ( $35 \& 45 \mathrm{~Hz}$ ), amplitude ( $3 \pm 0.5 \mathrm{~g} \& 9 \pm 0.5 \mathrm{~g}$ ), and exposure duration ( $30 \& 60$ seconds), i.e., were given to the study participants for 4 days. A random sampling of participants was conducted from two groups ( $\mathrm{n}=56$ /group), as follows: individuals with a Sedentary Lifestyle (SL) and a group of Construction Workers $(\mathrm{CW})$.

Results: Multivariate Analysis of Variance (MANOVA) results indicated a significant increase in EMG rms, median frequency, waveform length, mean absolute value $(\mathrm{P}<0.001)$, and the variance of EMG signal $(\mathrm{P}<0.05)$ (except in ECU for the SL group and ECRB for the $\mathrm{CW}$ group on the variance of EMG signal) after VT in all muscles of both research groups. Therefore, an increase in the EMG parameter value after a grip endurance task revealing an elevation in EMG signal amplitude is indicative of muscle fiber fatigue. Furthermore, the strongest correlation was found between grip endurance and $\mathrm{WL}(\mathrm{r}=0.471, \mathrm{P}<0.001)$, and EMG rms $(r=0.401, \mathrm{P}<0.001)$ of the ECU muscle in the SL group only.

Discussion: The patterns of EMG signal represented the amplitude and spectral parameters of the signal, enabling real-time fatigue analysis. Additionally, surface EMG information is useful for indirectly evaluating performance fatigue during the endurance test.

\section{"Corresponding Author:}

Abid Ali Khan, PhD.

Address: Ergonomics Research Division, Department of Mechanical Engineering, ZHCET, Faculty of Engineering \& Technology, Aligarh Muslim University, Aligarh, Uttar Pradesh, India.

Tel: +98 (919) 837111865

E-mail:abidak71@yahoo.com 


\section{Highlights}

- VT is believed to provide similar strength gains while limiting fatigue. Thus, it may be applied to workers in the construction industry.

- Current findings are examples of guidelines that may be useful to professional sports, clinical, rehabilitation, and medical therapists.

- The combination of high-frequency and low-amplitude, as well as low-frequency and high-amplitude, elicited greater activation of EMG activity in a shorter exposure.

\section{Plain Language Summary}

Vibration Therapy (VT) stimulates muscle spindles; thereby improving associated activity, allowing Motor Unit (MU) synchronization and generating further strength. The understanding/analysis of muscle fatigue is an important respecting prosthesis, functional electrical stimulation, and sports biomechanics. This study used surface Electromyography (EMG) information to present a multivariate approach using multiple EMG features to assess muscle fatigue during endurance testing. EMG surface data were found useful for indirectly assessing performance fatigue during the endurance test. Consequently, an increase in the value of the EMG parameter after an endurance task presented an elevation in the amplitude of the EMG signal, indicating the fatigue of muscle fibers. Therefore, the present study outcomes may be used as guidelines for professional sports, clinical, rehabilitation, and medical therapists.

\section{Introduction}

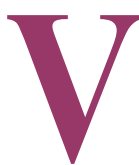

ibration Therapy (VT) stimulates muscle spindles; thereby improving associated activity, allowing Motor Unit (MU) synchronization, and generating further strength [1]. VT has been used to increase Electromyography (EMG) activity, power, and muscle strength [2]. Additionally, numerous researchers reported improvements in muscle performance using different frequencies of VT; $35 \mathrm{~Hz}[3-5]$ and $45 \mathrm{~Hz}[6,7]$. These have been observed where the muscle excitatory response plays a key role in improving muscle activation [8]. VT can reduce the pressure or tension in the belly of muscles. VT can also affect the viscoelastic aspects of the muscle tissue, leading to an increased ability to generate force [9]. Furthermore, muscular fatigue is a learning parameter of muscular performance. Information on optimal vibration training protocols is scarce. Specifically, the effects of various vibrational parameters on neuromuscular response and muscular fatigue remain unrecognized.

Muscle fatigue is a condition in which a muscle cannot produce the required or expected force [10]. Moreover, the extent of muscular fatigue can be evaluated by EMG activity [11]. The mean square root of the EMG signal increases with the intensity of muscular activity and the generation of force [11] with aggravated fatigue [12]. Researchers suggested that the increased recruit- ment of additional Motor Units (MUs) occurs due to a gradual increase in EMG activity [13-15]. A multivariate approach to assess fatigue was recommended; this is because multiple EMG features provide more information than a single feature [16].

Besides, spectral parameters, such as mean or median frequency and (amplitude features) such as root mean square; mean absolute value; EMG variance; and waveform length have been widely considered as the means of tracking muscle fiber fatigue over time [17, 18]. However, the amplitude measurements and spectral parameters described above may exhibit enhanced value-time discrepancies [16]. This is due to the non-stationary behavior of the EMG signal [19]. While measuring submaximal contraction, surface EMG signals elevate with fatigue. This process occurs due to the firing rate of MUs, and enhanced recruitment and synchronization of MUs within muscle fibers [14]. Numerous other approaches are also used to assess muscular fatigue viz., endurance tests; isometric strength test; muscle imaging; muscle biopsy; and surface Electromyography (sEMG) [20]; all of which aimed to compare muscle performance before and after the provision of therapy.

This study employed surface EMG data to present a multivariate approach. Accordingly, we used multiple EMG features to assess muscle fatigue during endurance testing. Therefore, the current study aimed to investigate 
fatigue in the muscle fibers of the forearm based on the pattern of EMG features. Such characteristics are considered as the indirect indices of performance fatigability during endurance testing by different VT protocols.

\section{Methods}

\section{Experimental Design}

A randomized comparative experimental design was used during the endurance test per $8 \mathrm{VT}$ protocols. The study was performed based on different combinations of vibration frequency $(35 \& 45 \mathrm{~Hz})[3-6,21]$, amplitude $(3 \pm 0.5 \mathrm{~g} \& 9 \pm 0.5 \mathrm{~g})[21,22]$, and exposure duration $(30 \&$ 60 seconds) [21], i.e., given to the research participants for 4 days. The pattern of muscle fatigue was evaluated concerning dependent variables, as follows: EMG rms; the Variance of EMG (VEMG); Mean Absolute Value (MAV); Waveform Length (WL), and Median Frequency (MDF) at 50\% MVC during the endurance test.

\section{Participants}

The present study was conducted from November 2018 to May 2019 at the Department of Mechanical Engineering, Aligarh Muslim University (AMU), Aligarh City, India. A random sampling of the study participants was performed in two groups ( $\mathrm{n}=56 /$ group); individuals with a Sedentary Lifestyle (SL) and a group of Construction Workers $(\mathrm{CW})$. All research participants were righthanded males and voluntarily participated in the current experiment. The study subjects reported no history of wrist or forearm dysfunction or other neurological conditions. Besides, they were examined by a physician at J N Medical College, AMU, Aligarh City, India. The SL group (staff/college students) were called from campus by notice. A group of CW were hired from the construction site and paid for participating in the current study in cash. The experimental protocol was explained to all study participants before the onset of the study. Table 1 presents the basic anthropometric measurements of the study participants.

\section{Experimental set-up}

The spring-loaded vibrating plate was designed to support the forearm in the supination position to deliver VT (Figure 1). The vibrator (15-65Hz) (model: Max JS113, $\mathrm{M} / \mathrm{s}$ Manipol) was centrally mounted below the vibrating plate, consisting of a small DC motor with an eccentric head. The eccentric masses of different diameters were also designed to provide the desired combination of frequency and amplitude.

\section{Experimental protocol}

To provide the VT, the research participants were requested to horizontally place their forearm in supination position on a platform with adjustable wrist support for the endurance test (Figure 1) and a vibrating plate during VT (Figure 2). The chair height was adjusted so that the study participant's right arm was in a coronal plane with $0^{\circ}$ abduction ensuring $90^{\circ}-120^{\circ}$ elbow angles. For

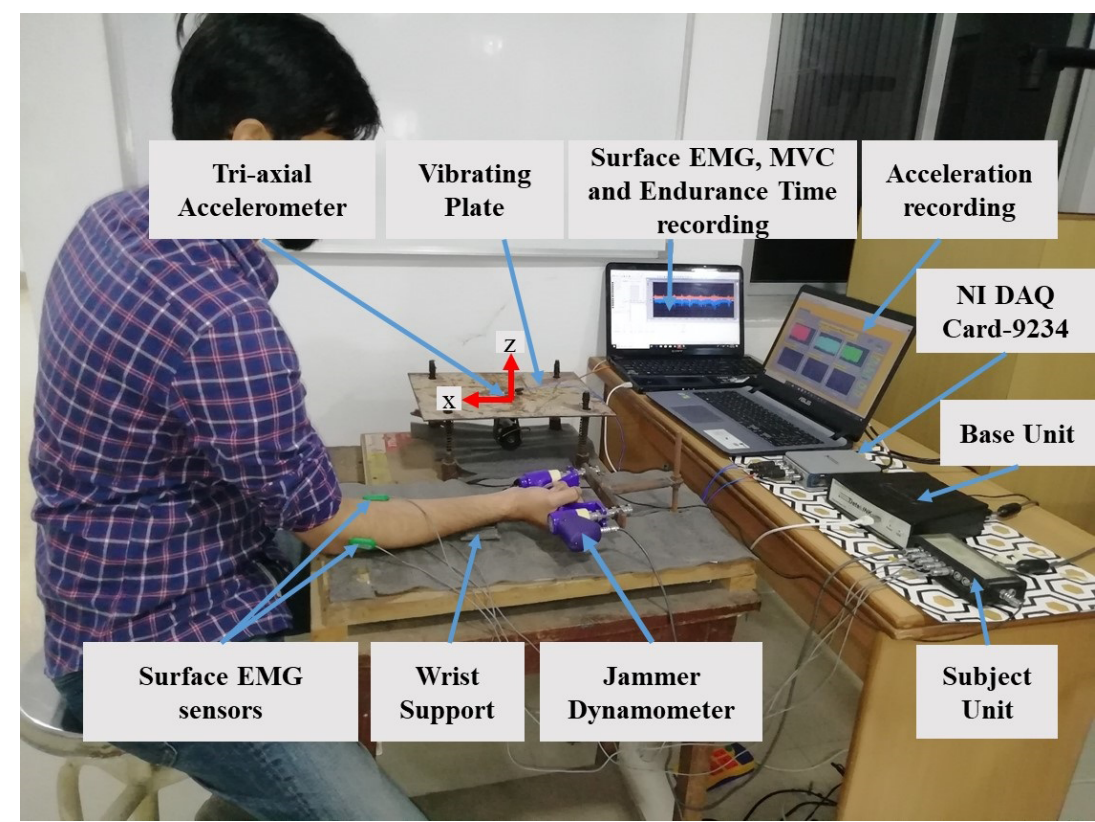

Figure 1. Experimental setup for recording the dependent variables 
Table 1. The characteristics of VT parameters and the anthropometric measurements of the study participants

\begin{tabular}{cccccc}
\hline VT Protocol & VT Frequency (Hz) & Amplitude (g) & Exposure Duration (sec) & \multicolumn{2}{c}{ Mean \pm SD/Age (y) } \\
\hline A & 35 & $3 \pm 0.5$ & 30 & SL Group & CW Group \\
\hline B & 35 & $3 \pm 0.5$ & 60 & $25.6 \pm 5.7$ & $29.6 \pm 11.9$ \\
\hline C & 35 & $9 \pm 0.5$ & 30 & $26.7 \pm 6.4$ & $39.7 \pm 14.1$ \\
\hline D & 35 & $9 \pm 0.5$ & 60 & $30.6 \pm 1.9$ & $31.4 \pm 10.3$ \\
\hline E & 45 & $3 \pm 0.5$ & 30 & $27.4 \pm 7.5$ & $28.6 \pm 7.1$ \\
\hline F & 45 & $3 \pm 0.5$ & 60 & $28.6 \pm 2.9$ & $21.9 \pm 3.8$ \\
\hline G & 45 & $9 \pm 0.5$ & 30 & $34.6 \pm 3.7$ & $23.4 \pm 2.2$ \\
H & 45 & $9 \pm 0.5$ & 60 & $24.1 \pm 3.9$ & $24.3 \pm 6.2$ \\
\hline
\end{tabular}

In each VT protocol, 7 study participants were recruited for the muscle training program.

Iranian Rehabilitation Journal

further details on the step-by-step experimental protocol, refer to Alam et al.'s study [21].

\section{Grip strength and endurance time measurement}

Each study participant had to squeeze the grip jammer dynamometer to its maximum capacity (twice with a 2-minute rest to record MVC) $[15,23]$ until the effort could not be maintained at the desired level. The Jammer dynamometer (Model: G100; Make: M/s Biometrics Ltd., UK) was directly interfaced with an 8-channel participant unit DataLINK using cable H2000; it was connected to the laptop by a USB1800 connecting lead. The endurance time was then recorded at 50\% MVC, while simultaneously acquiring EMG signals using DataLINK for subsequent analyses.

\section{Surface EMG recording and analyses}

EMG signals were recorded at a sampling frequency of $1024 \mathrm{~Hz}$ using a surface EMG electrode (SX230, M/s Biometrics Ltd. UK) with a 20 -mm center-to-center distance $[15,24,25]$. The reference electrode was placed on the wrist of the study subjects' non-dominant hand. Additionally, the surface EMG electrodes were attached on Flexor Digitorum Superficialis (FDS), Flexor Carpi

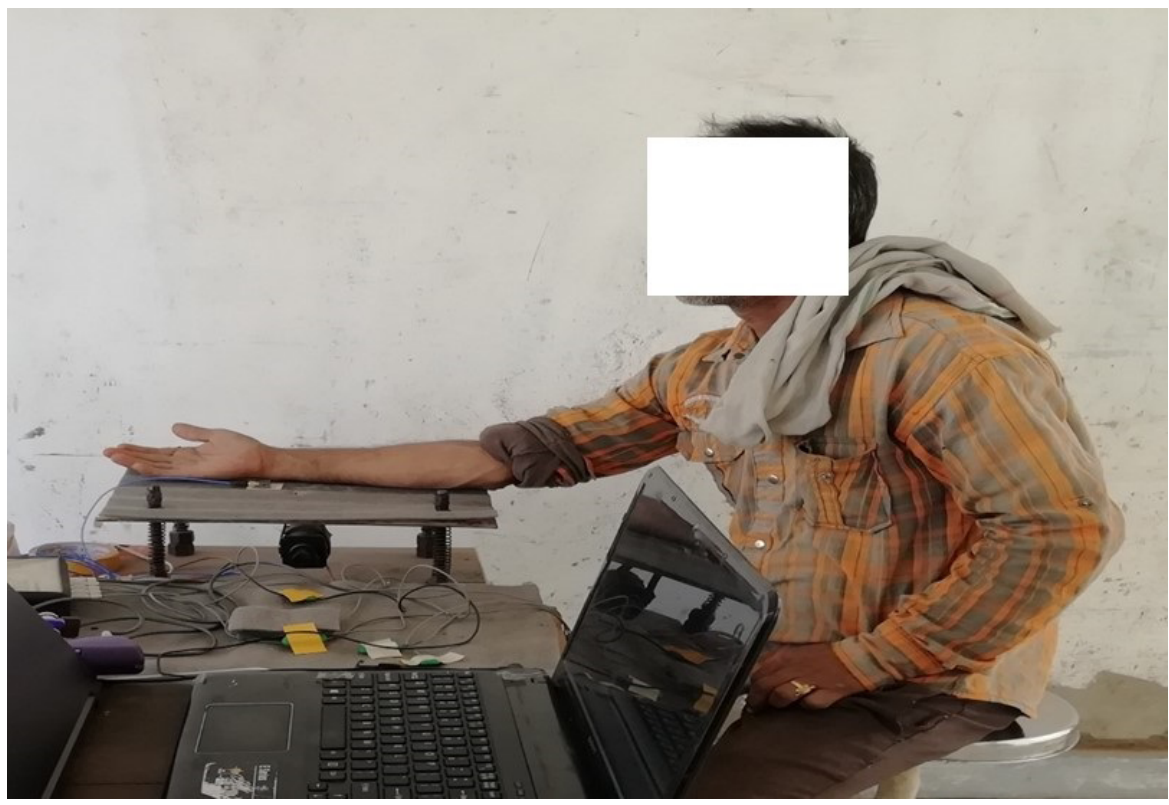

Figure 2. Forearm placed in supine posture on the spring loaded vibrating palate to deliver VT 
Table 2. The time domain and frequency domain features of the EMG signal

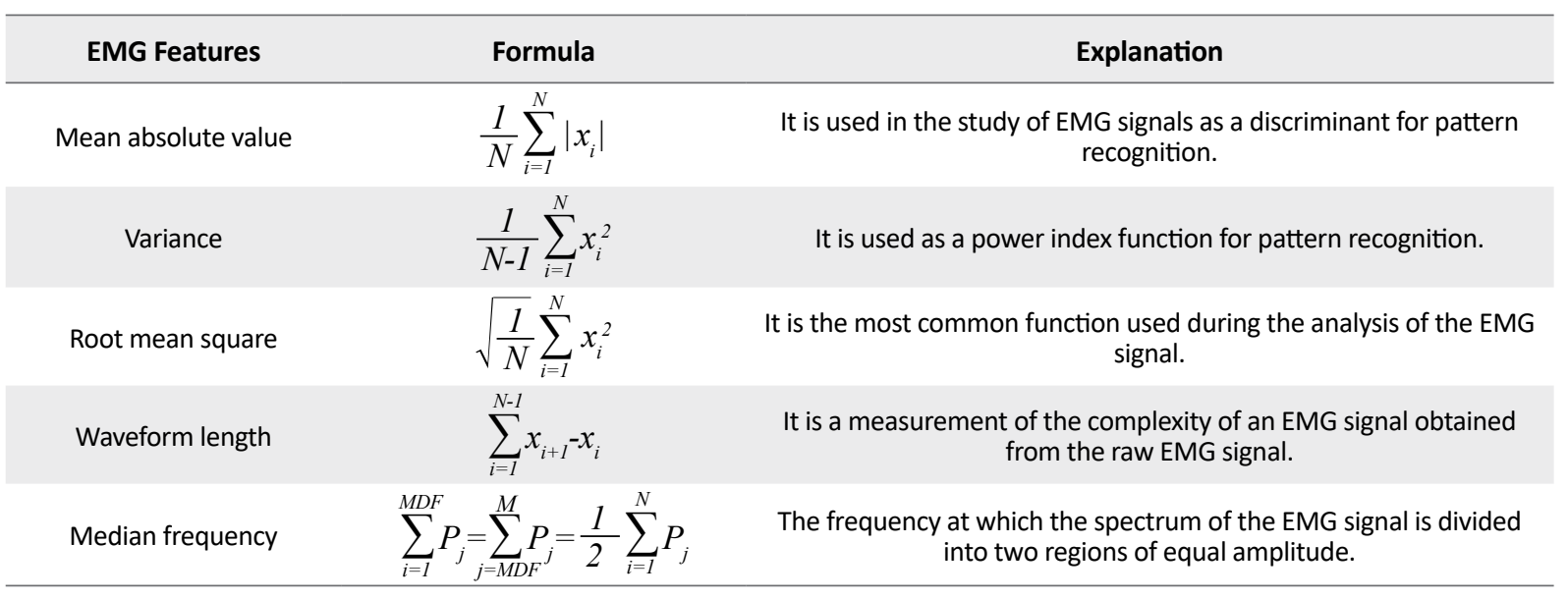

Iranian Rehabilitation Journa

Ulnaris (FCU), Extensor Carpi Ulnaris (ECU), and Extensor Carpi Radialis Brevis (ECRB) muscles [15, 26, 27]. These muscles were selected based on their functional significance in the gripping task [26]. Before placing the electrodes, the electrodes and the skin surface were washed with a cotton swab dipped in alcohol [15].

\section{Vibration level Recordings}

To measure the vibration level, a tri-axial accelerometer (model: SEN041F, manufacturer: Piezo Electronics PCB, New York, USA) was mounted at the center of the plate (Figure 1). The vibration level (g) was measured using an NI data acquisition card (National Instrument, DAQ Card-9234); it was connected to a laptop using LabVIEW12.0 code developed to capture, record, and analyze vibration signals.

\section{Feature extraction}

To evaluate the Neuromuscular Performance (NP) using EMG signals, the EMG features listed in Table 2 were applied [18]. A LABVIEW 12.0 vi was coded for the extraction of EMG features.

\section{Data analysis}

Multivariate Analysis of Variance (MANOVA) was used in SPSS (Table 3) to analyze the obtained data concerning the effects of VT protocols and the days of exposure to the features of EMG signals. Moreover, the Pearson correlation coefficient (Table 4) was employed to compute the relevant data of the grip endurance time and the features of the EMG signal.

\section{Results}

\section{EMG root mean square}

The days of exposure and VT protocols significantly affected the EMG rms of all muscles $(\mathrm{P}<0.001)$ in both research groups (Table 3 ). In the post-MANOVA tests, most of the improvements were observed on days 4 and 5 (SNK) in both research groups. Significant differences were detected in the interaction effect of VT protocols and the days of exposure for EMG rms in FDS $(\mathrm{P}<0.001)$ in the SL group. Figures 3 and 4 show an increase in EMG rms pattern in both study groups on day 4 after VT and on day 5 before vibration exposure (BVE) (except in ECRB for VT protocol $\mathrm{G}$ in $\mathrm{CW}$ ), compared to day 1 BVE in all muscles. The highest increase in EMG rms was reported in FCU for VT protocol $\mathrm{C}$ in the SL and VT protocol E in CW on the fourth day of VT. Besides, the Pearson correlation coefficient data (Table 4) regarding grip endurance time and EMG rms were significantly positive in all muscles of the study groups (except in the FDS \& ECRB muscles for the CW group) with the highest correlation coefficient $(\mathrm{r}=0.401, \mathrm{P}<0.001)$ in $\mathrm{ECU}$ muscle for the SL group.

\section{Median Frequency (MDF)}

The obtained results suggested the significant effect of VT protocols on the MDF of all muscles $(\mathrm{P}<0.001)$ in both study groups (Table 3 ). However, there was no significant effect concerning the days of exposure on the MDF of any muscles in the research groups. Significant differences were detected in the interaction effect of VT protocols and the days of exposure for MDF in ECRB muscle $(\mathrm{P}=0.004)$ among the $\mathrm{CW}$ group members. Figures 5 and 6 illustrate an increasing pattern in MDF values after day 
Table 3. The results of MANOVA concerning the dependent variables in the SL and CW groups

\begin{tabular}{|c|c|c|c|c|c|c|c|c|c|c|c|c|c|}
\hline \multirow{3}{*}{$\begin{array}{l}\text { 气̆ } \\
\text { ò }\end{array}$} & \multirow{3}{*}{ 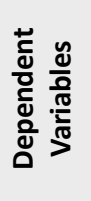 } & \multicolumn{12}{|c|}{ Independent Variables } \\
\hline & & \multicolumn{4}{|c|}{ VT Protocols } & \multicolumn{4}{|c|}{ Days of Exposure } & \multicolumn{4}{|c|}{$\begin{array}{l}\text { VT Protocols and the Days of } \\
\text { Exposure }\end{array}$} \\
\hline & & FDS & FCU & ECRB & ECU & FDS & FCU & ECRB & ECU & FDS & FCU & ECRB & ECU \\
\hline \multirow{5}{*}{ 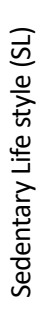 } & RMS & $<0.001^{* *}$ & $<0.001^{* *}$ & $<0.001^{* *}$ & $0.017^{*}$ & $<0.001^{* *}$ & $<0.001^{* *}$ & $<0.001^{* *}$ & $<0.001^{* *}$ & $<0.001^{* *}$ & $0.149^{\#}$ & $0.898^{\#}$ & $0.566^{\#}$ \\
\hline & MDF & $<0.001^{* *}$ & $<0.001^{* *}$ & $<0.001^{* *}$ & $<0.001^{* *}$ & $0.278^{\#}$ & $0.656^{\sharp}$ & $0.411^{\#}$ & $0.254^{\#}$ & $1.000^{\sharp}$ & $0.878^{\#}$ & $0.752^{\#}$ & $0.084^{\#}$ \\
\hline & VAR & $<0.001^{* *}$ & $<0.001^{* *}$ & $<0.001^{* *}$ & $0.153^{\#}$ & $0.576^{\#}$ & $0.336^{\#}$ & $0.491^{\#}$ & $0.581^{\#}$ & $0.276^{\#}$ & $0.291^{\#}$ & $<0.001^{* *}$ & $0.356^{\#}$ \\
\hline & WL & $<0.001^{* *}$ & $<0.001^{* *}$ & $<0.001^{* *}$ & $<0.001^{* *}$ & $0.066^{\#}$ & $<0.001^{* *}$ & $<0.001^{* *}$ & $<0.001^{* *}$ & $0.963^{\#}$ & $0.978^{\#}$ & $0.027^{*}$ & $0.128^{\#}$ \\
\hline & MAV & $<0.001^{* *}$ & $<0.001^{* *}$ & $<0.001^{* *}$ & $<0.001^{* *}$ & $0.166^{\#}$ & $<0.001^{* *}$ & $0.069^{\#}$ & $0.039^{*}$ & $0.157^{\#}$ & $0.016^{*}$ & $<0.001^{* *}$ & $<0.001^{* *}$ \\
\hline \multirow{5}{*}{ 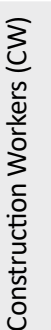 } & RMS & $<0.001^{* *}$ & $<0.001^{* *}$ & $0.025^{*}$ & $<0.001^{* *}$ & $0.003^{*}$ & $<0.001^{* *}$ & $<0.001^{* *}$ & $<0.001^{* *}$ & $0.989^{\#}$ & $0.080^{\#}$ & $0.155^{\#}$ & $0.667^{\#}$ \\
\hline & MDF & $<0.001^{* *}$ & $<0.001^{* *}$ & $<0.001^{* *}$ & $<0.001^{* *}$ & $0.347^{\sharp}$ & $0.314^{\#}$ & $0.819^{\#}$ & $0.595^{\#}$ & $0.320^{\sharp}$ & $0.645^{\#}$ & $0.004^{*}$ & $0.780^{\#}$ \\
\hline & VAR & $<0.001^{* *}$ & 0.045 & 0.498 & $<0.001^{* *}$ & $0.698^{\#}$ & $0.850^{\#}$ & $0.102^{\#}$ & $0.002^{*}$ & $0.336^{\#}$ & $0.916^{\#}$ & $0.283^{\#}$ & $0.002^{*}$ \\
\hline & WL & $<0.001^{* *}$ & $<0.001^{* *}$ & $<0.001^{* *}$ & $<0.001^{* *}$ & $0.336^{\#}$ & $0.385^{\#}$ & $0.271^{\#}$ & $0.375^{\#}$ & $0.189^{\#}$ & $0.635^{\#}$ & $0.449^{\#}$ & $0.404^{\#}$ \\
\hline & MAV & $<0.001^{* *}$ & $<0.001^{* *}$ & $0.107^{\#}$ & $<0.001^{* *}$ & $0.920^{\#}$ & $0.589^{\#}$ & $0.138^{\#}$ & $0.002^{*}$ & $0.041^{*}$ & $0.649^{\#}$ & $0.779^{\#}$ & $0.074^{\#}$ \\
\hline
\end{tabular}

** $\mathrm{P}<0.001,{ }^{*} \mathrm{P}<0.05, \# \mathrm{P}>0.05$ (not significant).

Iranian Rehabilzation Journal

4 of VT and on day 5 of be, compared to day 1 post BVE in most of the muscles and VT protocols in both study groups. Pearson correlation coefficient (Table 4) respecting grip endurance time and the MDF was found to be significant in FDS $(r=0.159, \mathrm{P}<0.001), \mathrm{ECRB}(\mathrm{r}=0.125$, $\mathrm{P}=0.008)$, and $\operatorname{ECU}(\mathrm{r}=0.169, \mathrm{P}<0.001)$ in the $\mathrm{SL}$ group; interestingly, there was a negative correlation in FDS muscle $(\mathrm{r}=-0.168, \mathrm{P}<0.001)$ in the $\mathrm{CW}$ group.

\section{Variance of EMG signal (VAR)}

VT protocols significantly influenced the variance of EMG signal in FDS, FCU, and ECRB $(\mathrm{P}<0.001)$ in the
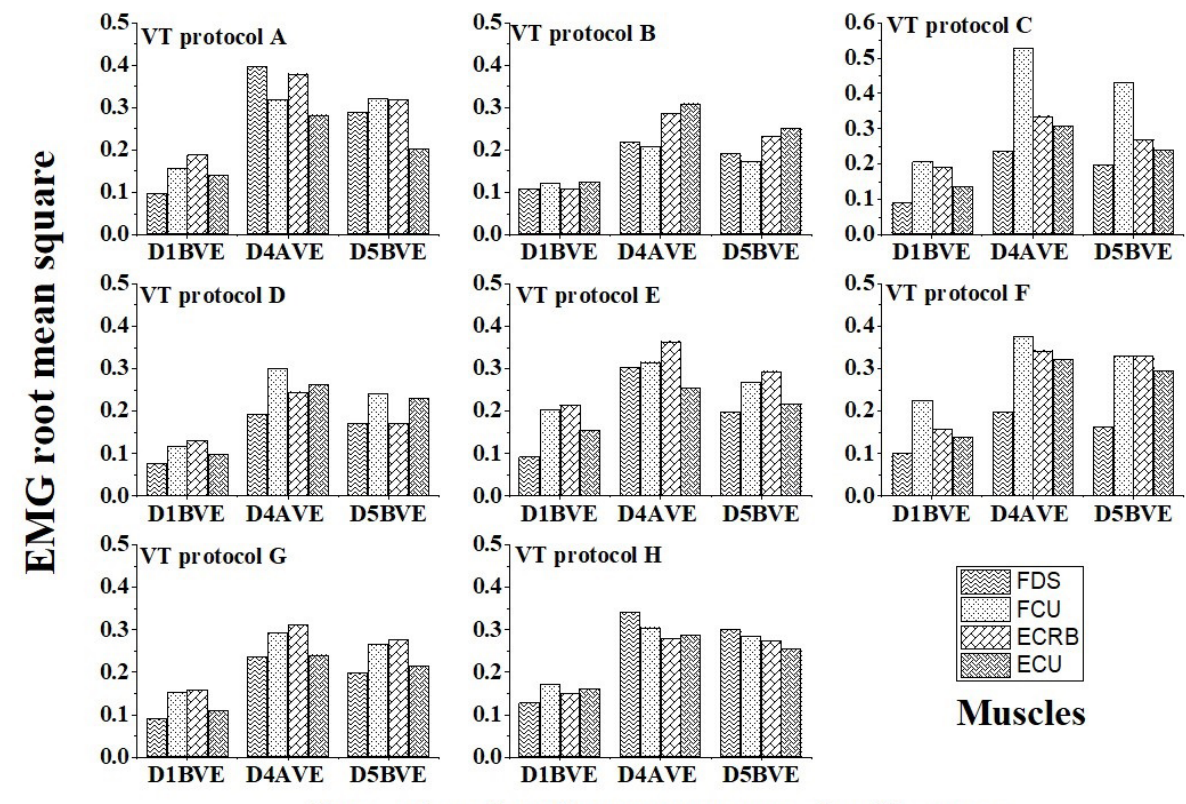

Days wise vibration exposure on the SL group

Figure 3. The EMG rms values for the SL group in all muscles with respect to VT protocols 

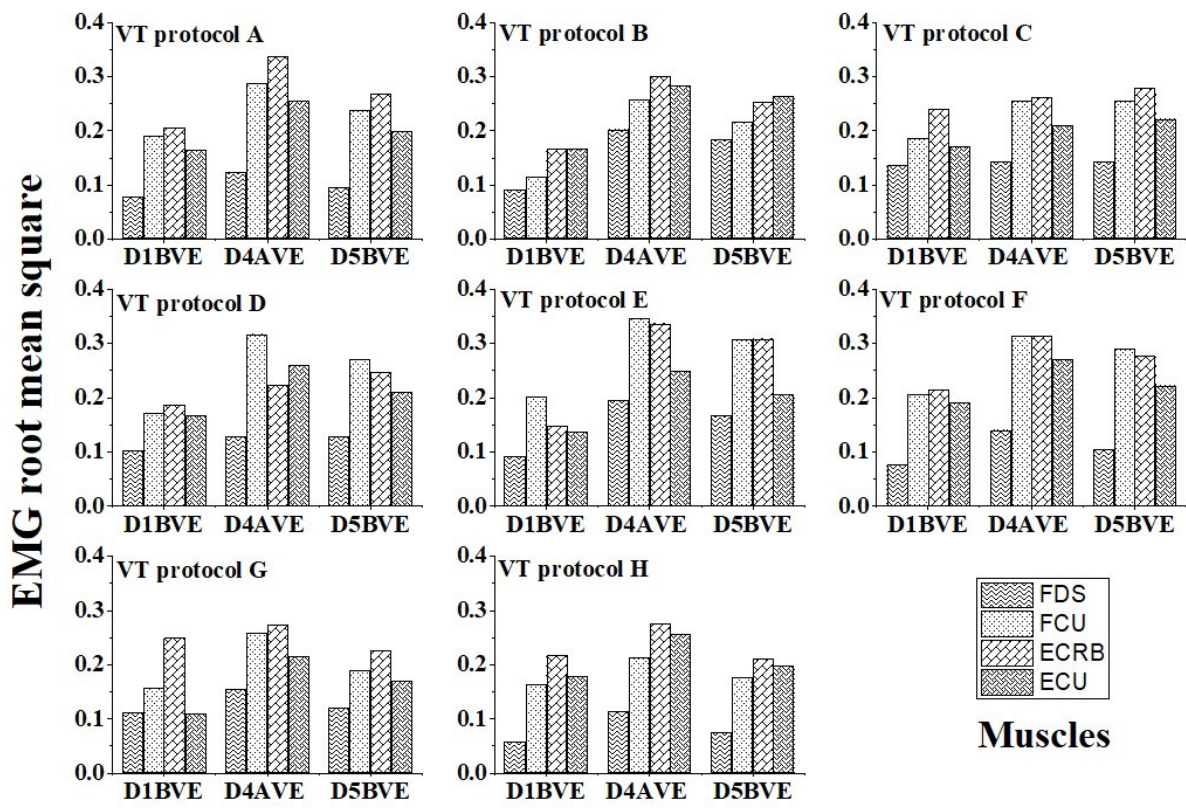

Muscles

Days wise vibration exposure on the $\mathrm{CW}$ group

Figure 4. The EMG rms values for the CW group in all muscles with respect to VT protocols

Iranian Rehabilitation Journal

SL group; there was no such impact with FDS $(\mathrm{P}<0.001)$, FCU $(\mathrm{P}=0.045)$, and ECU $(\mathrm{P}<0.001)$ in the $\mathrm{CW}$ group (Table 3). However, the days of exposure indicated a significant effect on VAR in ECU $(\mathrm{P}=0.002)$ in the CW group. Significant differences were found in the interaction effects of VT protocols and the days of exposure for VAR in ECRB muscle $(\mathrm{P}<0.001)$ in the SL group as well as ECU $(\mathrm{P}=0.002)$ in the $\mathrm{CW}$ group. Figures 7 and 8 demonstrate an increasing pattern in VAR values on day 4 of VT and day 5 of be, compared to day 1 postBVE in most of the muscles and VT protocols in both research groups. The highest increase in VAR was found in ECRB muscle for VT protocol $\mathrm{E}$ in both study groups. Interestingly, there was a significant negative correlation
(Table 4) between grip endurance time and the VAR of the EMG signal in FDS muscle in the research groups.

The VT protocols provided a significant effect on Waveform Length (WL) in all muscles $(\mathrm{P}<0.001)$ in both research groups (Table 3 ). Moreover, the days of exposure significantly influenced WL values in FCU, ECRB, and ECU $(\mathrm{P}<0.001)$ in the SL group. Significant differences were observed concerning the interaction effect of VT protocols and the days of exposure for WL in ECRB $(\mathrm{P}=0.027)$ in the SL group. Figures 9 and 10 illustrate an increasing pattern in WL values on day 4 post-VT and day 5 after be, compared to day 1 post-BVE in most of the muscles and VT protocols in both research groups. Pearson correlation coefficient (Table 4) respecting grip

Table 4. The results of the Pearson correlation coefficient $(r)$ between the grip endurance time and EMG features

\begin{tabular}{|c|c|c|c|c|c|c|c|c|c|}
\hline \multirow{2}{*}{\multicolumn{2}{|c|}{ Variables }} & \multicolumn{4}{|c|}{ SL Group (n=56) } & \multicolumn{4}{|c|}{ CW Group $(n=56))$} \\
\hline & & FDS & FCU & ECRB & ECU & FDS & FCU & ECRB & ECU \\
\hline \multirow{5}{*}{ EMG Features } & RMS & $\begin{array}{l}(r=0.329 \\
P<0.001)\end{array}$ & $\begin{array}{l}(r=0.353 \\
P<0.001)\end{array}$ & $\begin{array}{l}(r=0.312, \\
P<0.001)\end{array}$ & $\begin{array}{l}(r=0.401, \\
P<0.001)\end{array}$ & $\#$ & $\begin{array}{l}(r=0.110, \\
P=0.020)\end{array}$ & \# & $\begin{array}{l}(r=0.234, \\
P<0.001)\end{array}$ \\
\hline & MDF & $\begin{array}{l}(r=0.159 \\
P<0.001)\end{array}$ & $\#$ & $\begin{array}{l}(r=0.125, \\
P=0.008)\end{array}$ & $\begin{array}{l}(r=0.169 \\
P<0.001)\end{array}$ & $\begin{array}{l}(r=-0.168, \\
P<0.001)\end{array}$ & $\#$ & $\#$ & $\#$ \\
\hline & VAR & $\begin{array}{l}(r=-0.101, \\
P=0.032)\end{array}$ & $\#$ & $\#$ & $\#$ & $\begin{array}{c}(r=-0.116, \\
P=0.014)\end{array}$ & $\#$ & $\#$ & $\#$ \\
\hline & WL & $\begin{array}{l}(r=0.207 \\
P<0.001)\end{array}$ & $\begin{array}{l}(r=0.434, \\
P<0.001)\end{array}$ & $\begin{array}{l}(r=0.450, \\
P<0.001)\end{array}$ & $\begin{array}{l}(r=0.471 \\
P<0.001)\end{array}$ & $\begin{array}{l}(r=0.294 \\
P<0.001)\end{array}$ & $\begin{array}{l}(r=0.299, \\
P<0.001)\end{array}$ & $\begin{array}{l}(r=0.335 \\
P<0.001)\end{array}$ & $\begin{array}{l}(r=0.409, \\
P<0.001)\end{array}$ \\
\hline & MAV & $\begin{array}{l}(r=0.119 \\
P=0.012)\end{array}$ & $\begin{array}{l}(r=0.182 \\
P<0.001)\end{array}$ & $\#$ & $\begin{array}{l}(r=0.149 \\
P=0.002)\end{array}$ & $\#$ & $\#$ & $\#$ & $\#$ \\
\hline
\end{tabular}



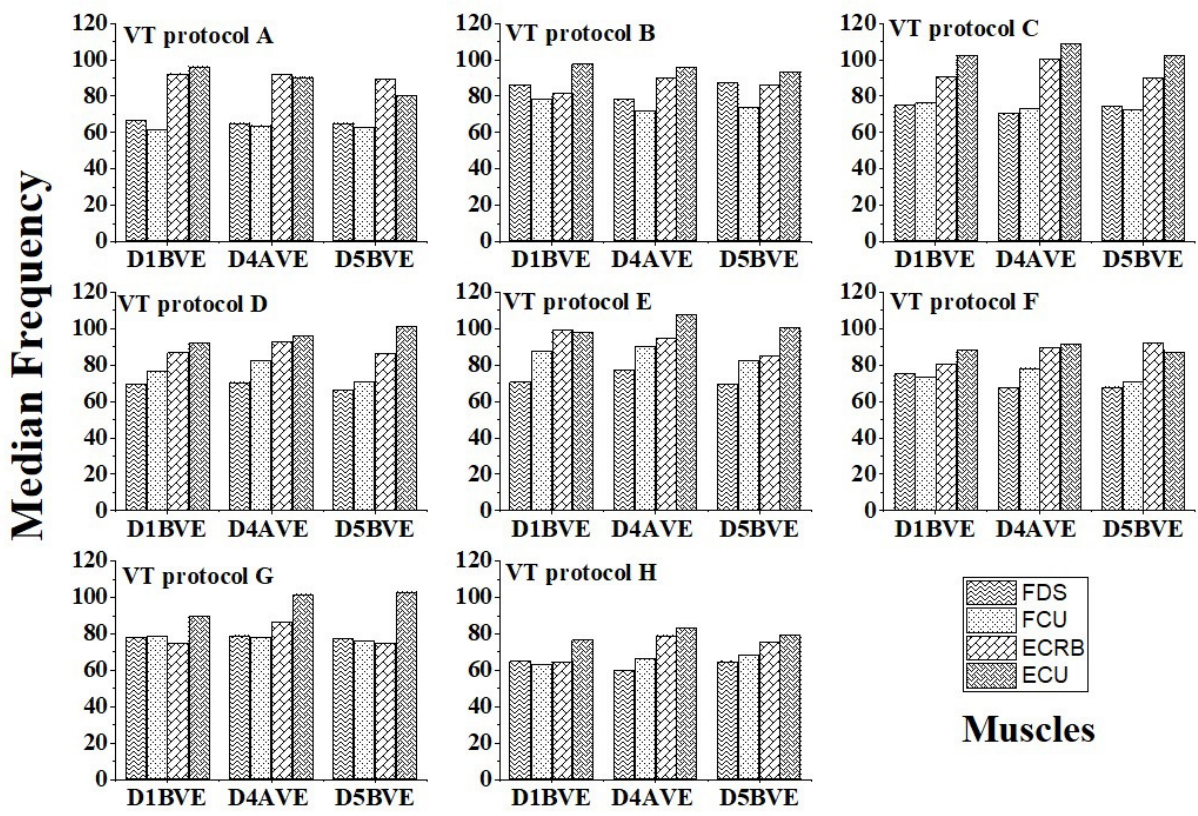

Muscles

Days wise vibration exposure on the SL group

Figure 5. Median frequency values for the SL group in all muscles with respect to VT protocols

Iranian Rehabilitation Journal

endurance time and the WL was found significantly positive in all muscles of the study groups with the highest correlation coefficient $(\mathrm{r}=0.471, \mathrm{P}<0.001)$ belonging to ECU muscle in the SL group.

The VT protocols signified a significant effect on Mean Absolute Value $(\mathrm{MAV})$ in all muscles $(\mathrm{P}<0.001)$ (except in ECRB in the CW group) in both research groups
(Table 3). The days of exposure provided a significant impact on the MAV values in FCU $(\mathrm{P}=0.001)$ and ECU $(\mathrm{P}=0.039)$ in the SL group; however, there were such effects detected in ECU $(\mathrm{P}=0.002)$ in the $\mathrm{CW}$ group. Significant differences were found in the interaction effect of $\mathrm{VT}$ protocols and the days of exposure for MAV in FCU $(\mathrm{P}=0.016), \operatorname{ECRB}(\mathrm{P}=0.001)$, and $\operatorname{ECU}(\mathrm{P}<0.001)$ in the $\mathrm{SL}$ group; the same was observed in $\operatorname{FDS}(\mathrm{P}=0.004)$ in
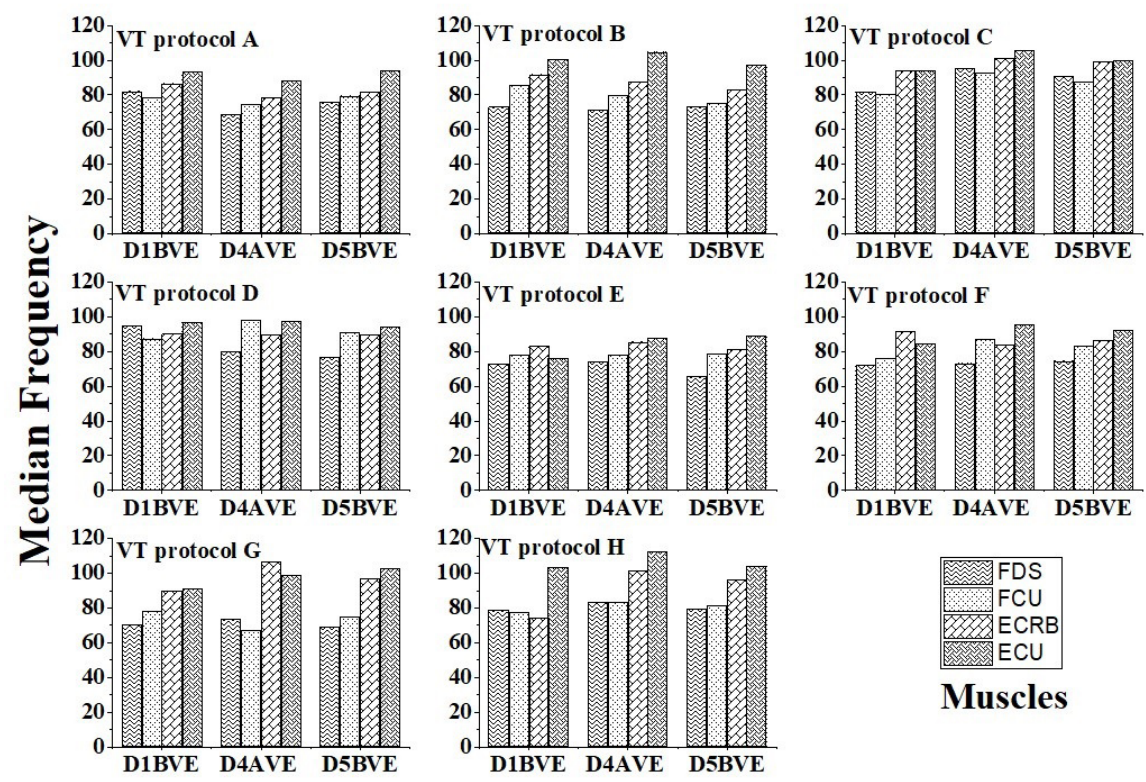

Muscles

Days wise vibration exposure on the $C W$ group

Figure 6. Median frequency values for the CW group in all muscles with respect to VT protocols 

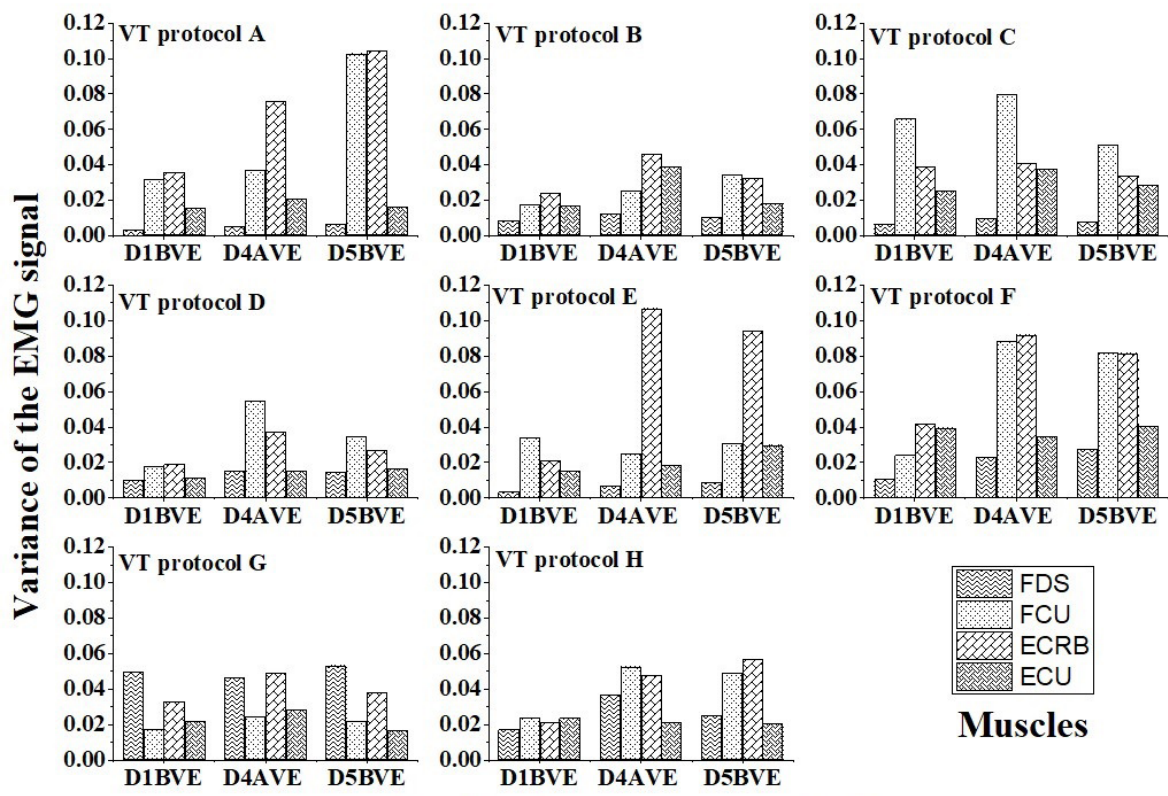

Days wise vibration exposure on the SL group

Figure 7. Variance of EMG signal values for the SL group in all muscles with respect to VT protocols

the CW group. Figures 11 and 12 illustrate an increasing pattern in MAV values on day 4 after VT and day 5 post be, compared to day 1 after BVE in most muscles and VT protocols in both research groups. The highest increase in MAV was reported in FCU muscles for VT protocol $\mathrm{C}$ in the SL group and VT protocol $\mathrm{F}$ for the $\mathrm{CW}$ group. Additionally, Pearson correlation coefficient (Table 4) on grip endurance time and MAV was found significant in FDS $(\mathrm{r}=0.119, \mathrm{P}=0.012), \mathrm{FCU}(\mathrm{r}=0.182$, $\mathrm{P}<0.001)$, and $\mathrm{ECU}(\mathrm{r}=0.149, \mathrm{P}=0.002)$ in the SL group.

\section{Discussion}

The maximum EMG amplitude represents the activity of the maximum number of detectable motor units that fire at their maximum speed, i.e., usually measured in
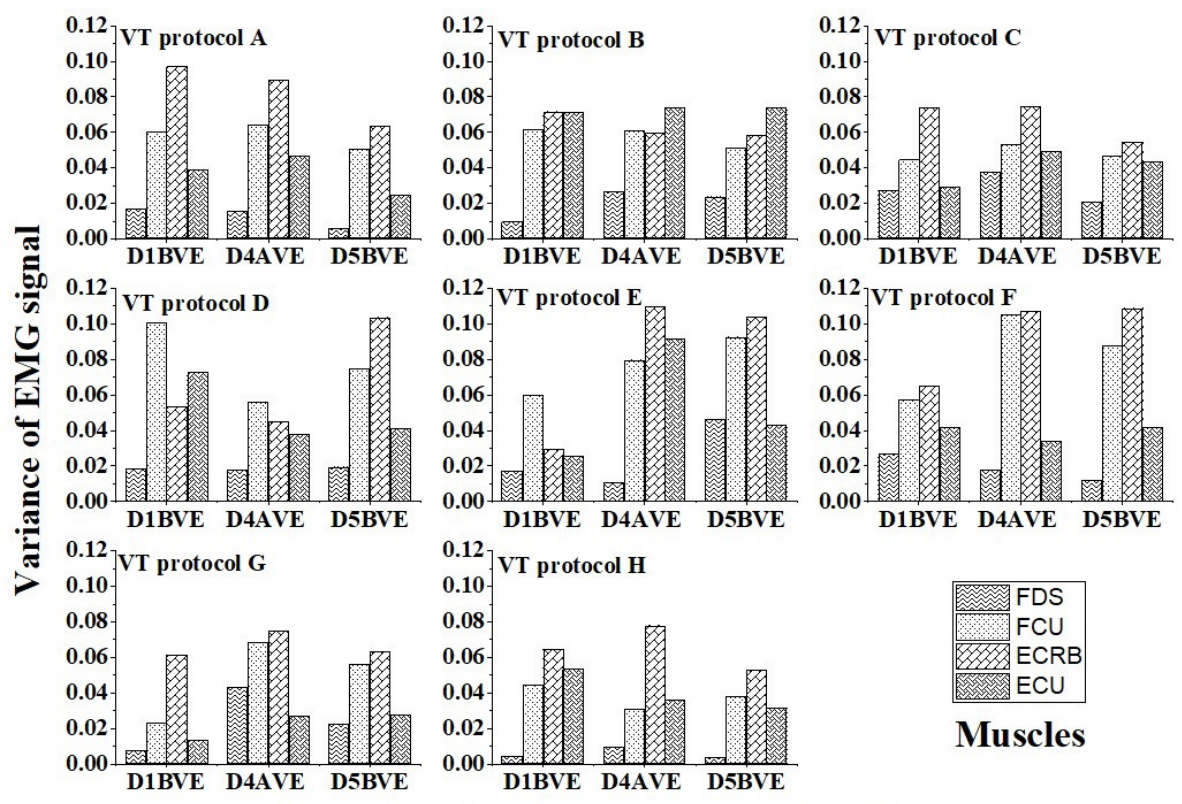

Days wise vibration exposure on the $C W$ group

Figure 8. Variance of EMG signal values for the CW group in all muscles with respect to VT protocols

Iranian Rehabilitation Journal 


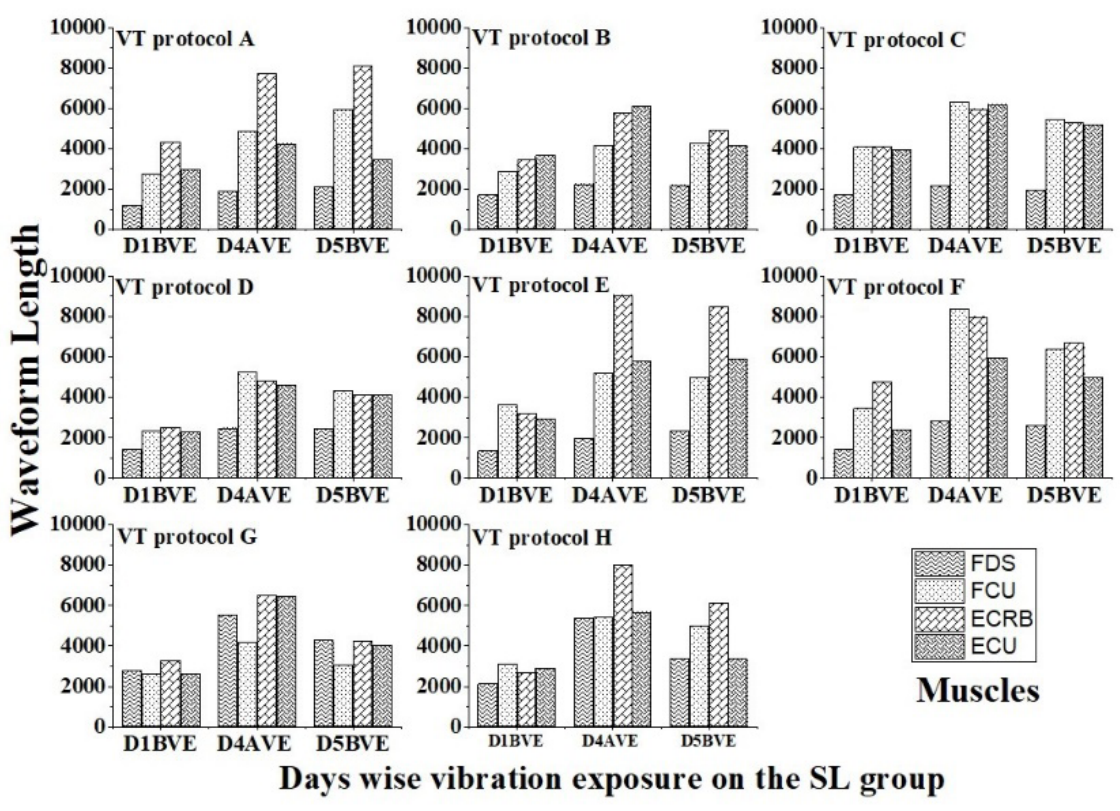

Figure 9. Waveform length value for the SL group in all muscles with respect to VT protocols

Iranian Rehabilitation 】ournal

short-term MVC. In line with the current results, several studies reported a significant increase in EMG activity after VT [2-5, 7]. However, few studies suggested no such significant effects $[6,8]$. Failure to generate peak EMG amplitudes corresponding to the maximum values may be due to the reduced recruitment of motor units induced by central or peripheral fatigue [28]. An elevation was observed in EMG rms in all muscles after VT during grip endurance task at 50\% MVC in this study. Such data might be attributed to the replacement of fresh motor units used to compensate for the reduced performance of motor units in fatigued muscles [15, 29]. Therefore, an increase in the EMG parameter value after a grip endurance task reveals an enhancement in EMG signal amplitude; it is indicative of muscle fiber fatigue. However, the highest correlation was found between grip endurance time and EMG rms $(\mathrm{r}=0.401, \mathrm{P}<0.001)$ in $\mathrm{ECU}$ muscle in the SL group. In contrast, ECRB muscle was reported to exhibit a higher fatigue response than FDS and FCU muscles [15].

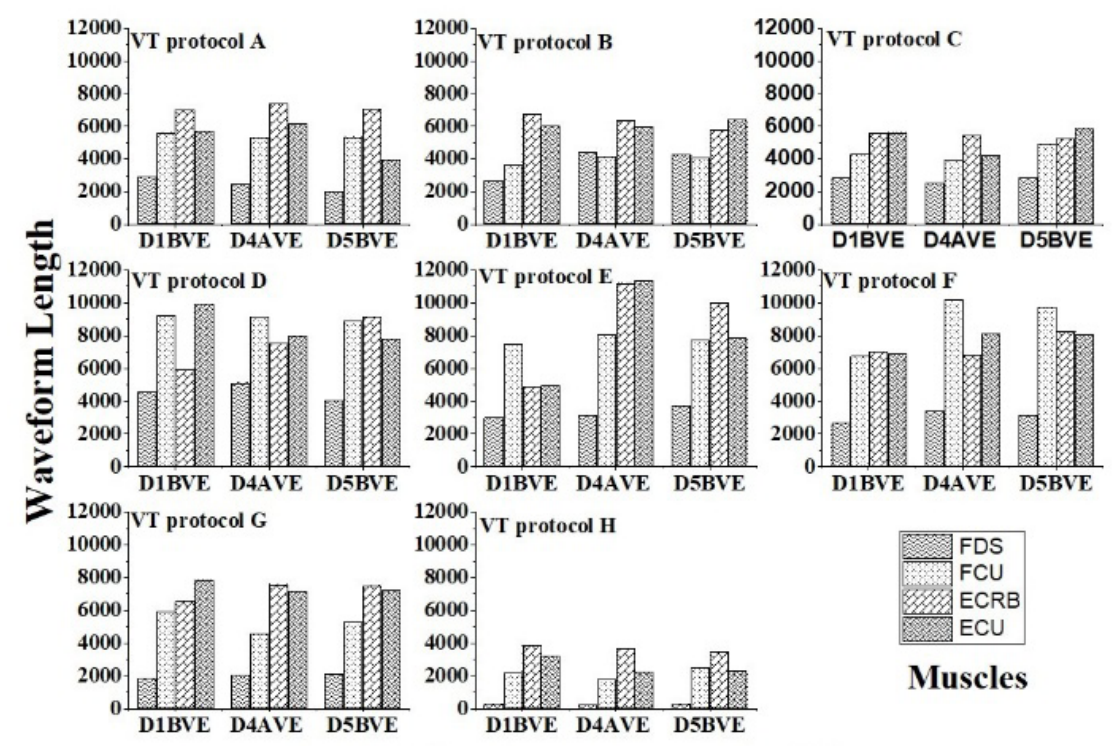

Days of vibration exposure on the $\mathrm{CW}$ group

Figure 10. Waveform length value for the $\mathrm{CW}$ group in all muscles with respect to VT protocols 

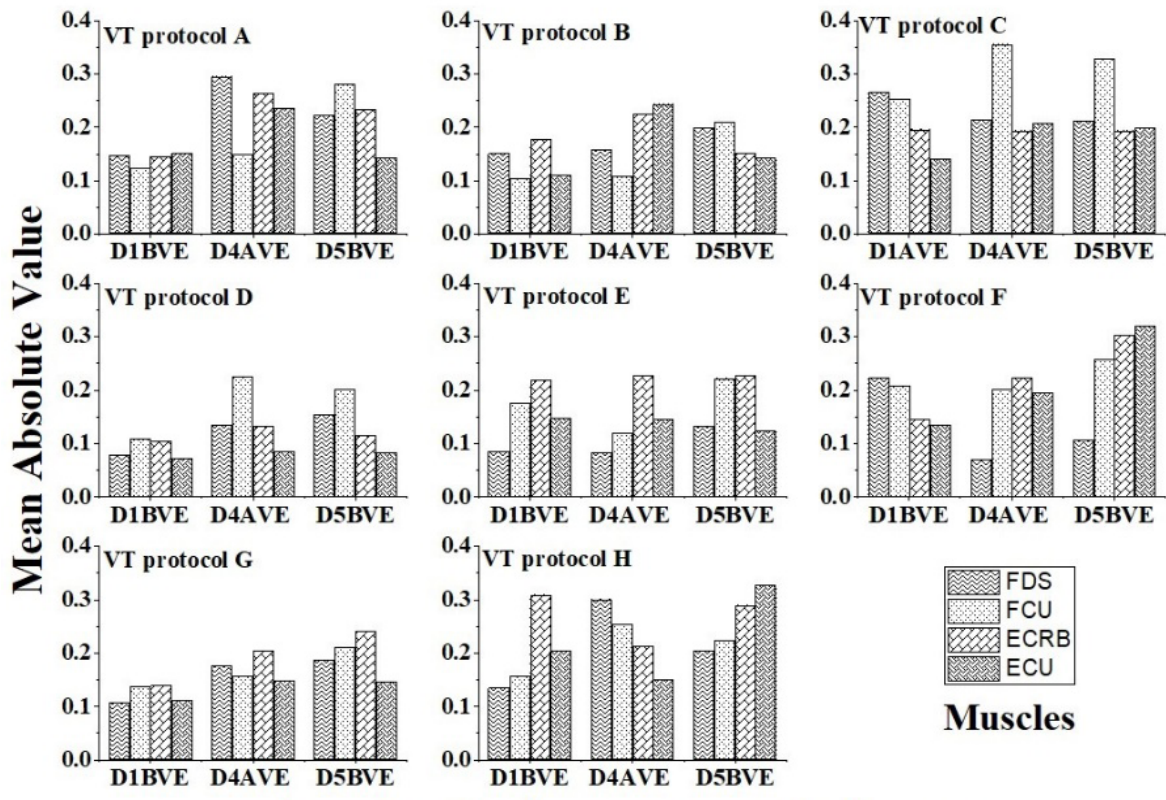

Muscles

Days wise vibration exposure on the SL group

Figure 11. Mean absolute value for the SL group in all muscles with respect to VT protocols

Iranian Rehabilitation Journal

Moreover, the current study results manifested that the highest fatigue was recorded in FCU muscle based on the elevation in EMG amplitude for VT protocol $\mathrm{E}$ corresponding to the $\mathrm{CW}$ group (Mean $\pm \mathrm{SD}$ age: $21.9 \pm 3.8$ years). Furthermore, the SL group reported maximum Flexor Fatigue Ulnaris (FCU) for VT protocol C (Mean \pm SD age: $30.6 \pm 1.9$ years). Interestingly, in an in-house study [21], grip strength was highest for VT protocol $\mathrm{E}$ in the $\mathrm{CW}$ group (Mean $\pm \mathrm{SD}$ age: $\geq 21.9 \pm 3.8$ years) participants; older participants in the $\mathrm{CW}$ group (39.7 \pm 14 .1 years) had a longer endurance (VT protocol B), compared to the younger age group (VT protocol E). Similarly, Hunter et al. [30] found higher grip endurance for older participants than the younger subjects.

Furthermore, Mogk et al. [27] concluded that muscle activation was primarily dependent on forearm posture;
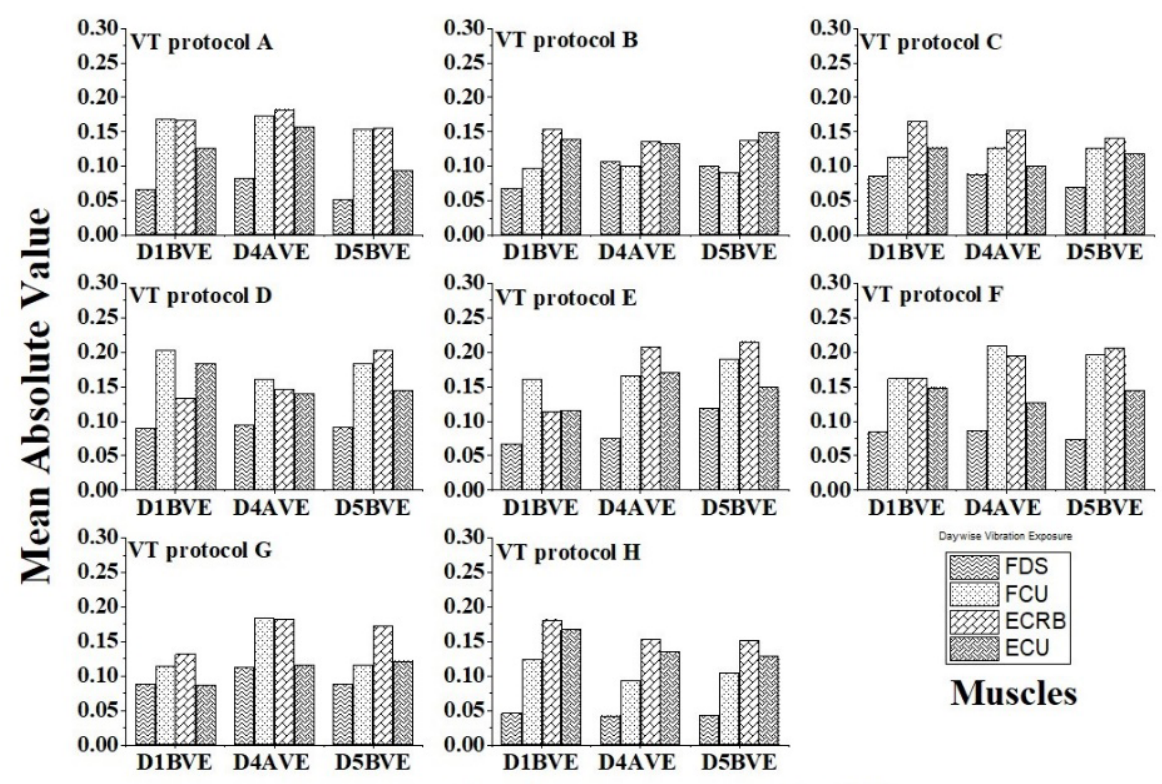

Days wise vibration exposure on the $C W$ group

Figure 12. Mean absolute value for the $\mathrm{CW}$ group in all muscles with respect to VT protocols 
with supination flexor activation being the strongest and greater extensor muscle activation in pronation. The obtained data also signified maximal muscle activation in FCU in both study groups after VT. Contrarily, Loren et al. [31] reported that ECRB muscle activity was greater than that of ECU in supination position. Thus, per Mogk et al. [27], the collected results reflected that flexor activation is greater than extensor activation in supination. In other words, the combination of high frequency-low amplitude and low frequency-high amplitude elicited the greater activation of EMG activity with a shorter duration of exposure.

Griffin et al. [13] documented an increase in the firing rate of triceps brachii muscle during prolonged contractions after exposure to vibration. Similarly, current results indicated that all VT protocols in both study groups significantly increased MDF patterns in most muscles. In contrast, Tanaka et al. [32] reported a significant decrease in MDF over time, without significant differences in MDF and EMGrms values before and after massage. Another study reported that the new spectral index is better than MDF under dynamic conditions. This is because MDF is a reliable and valid parameter in static conditions for evaluating fatigue [33]. Thus, MDF is frequently used as a gold standard tool to detect target muscle fatigue using EMG signals; however, the impact of muscle strength on MDF remains inconclusive [34]. However, the present research results suggested a poor correlation between grip endurance time and MDF in all muscles of both study groups.

The representation of the variance of the rectified signal is more complex. This is because it includes all the terms present in the EMG rms and integrated EMG parameters. Furthermore, an increase in MAV indicates an elevation in the amplitude of the EMG signal; accordingly, it increases the level of muscle fiber fatigue [15]. Similarly, the obtained data revealed an increase in MAV and WL, indicating an enhanced amplitude of EMG signal, leading to elevated levels of muscle fiber fatigue. Similarly, Viitasalo and Komi [35] analyzed the sEMG signal of rectus femoris muscle during static contractions; subsequently, they reported an increase in the MAV of EMG signal induced by fatigue. We also observed that most muscle and VT protocols in both study groups adopted an increasing trend in VAR, MAV, and WL values on day 4 of VT, compared to day 1 post BVE; thus, there was an increase in the value of the EMG parameter after a grip endurance task. Accordingly, there existed an increase in the amplitude of EMG signal indicates muscle fiber fatigue. Moreover, the current research findings indicated that short-term exposure in the same posture during the
VT protocol limits muscle relaxation and may primarily contribute to fatigue.

Only the short-term (4 day) effects of VT were studied in this investigation. During the VT, the low-level discomfort was ignored. This may have hindered enhancement in muscle performance. Therefore, further examinations are required to more precisely describe the following factors: the optimal frequency; exposure duration; amplitude parameters; and the number of days for training. Besides, further EMG features may be extracted to assess the fatigue patterns of the muscle fibers.

\section{Conclusion}

The current research results indicated an increase in EMG signal amplitude and spectral parameter values; such data can be used to detect fatigability in both groups during an endurance task. Therefore, surface EMG signals can be used as indirect indicators of performance fatigability.

\section{Ethical Considerations}

\section{Compliance with ethical guidelines}

The experimental protocol was approved by the Departmental Ethics Committee (No. EC/60/2017). All study participants provided written informed consent forms and were allowed to terminate the experiment at any stage.

\section{Funding}

This study was performed based on the project funded by CSIR (NEW DELHI, PUSA) GRANT_NUMBER: 141530/2K15/1, File No. 09/112(0553)2K17-EMR-I.

\section{Authors' contributions}

Conceptualization and investigation, writing the original draft: Mohd Mukhtar Alam, Abid Ali Khan; Methodology, supervision, writing, review, and editing the manuscript: Mohd Mukhtar Alam, Abid Ali Khan; Resources: Mohd Mukhtar Alam, Abid Ali Khan.

\section{Conflict of interest}

The authors declared no conflicts of interest.

\section{Acknowledgments}

The authors would like to thanks the Council of Scientific \& Industrial Research (CSIR), Human Resource 
Development Group, New Delhi, India, for awarding Senior Research Fellowship (SRF). The authors are also grateful for the help provided by physician of J N Medical College, AMU, Aligarh City, India.

\section{References}

[1] Souron R, Besson T, Millet G, Lapole T. Acute and chronic neuromuscular adaptations to local vibration training. European Journal of Applied Physiology. 2017; 117(10):1939-64. [DOI:10.1007/s00421-017-3688-8] [PMID]

[2] Alam MM, Khan AA, Farooq M. Effect of whole-body vibration on neuromuscular performance: A literature review. Work. 2018;59(4):571-83. [DOI:10.3233/WOR-182699] [PMID]

[3] Di Giminiani R, Masedu F, Tihanyi J, Scrimaglio R, Valenti $M$. The interaction between body position and vibration frequency on acute response to whole body vibration. Journal of Electromyography and Kinesiology. 2013; 23(1):245-51. [DOI:10.1016/j.jelekin.2012.08.018] [PMID]

[4] Moawd SA, Abdelhalem NM, Samhan AF, Mahmoud WS, Effects of whole-body vibration and resistance training on muscular performance in young adults. Journal of American Science. 2014; 10(1):67-73. http://free-journal.umm.ac.id/ files/file/014_22678am1001_2014_67_73.pdf

[5] Alam MM, Khan AA, Farooq M, Bhardwaj S. Effect of one week intervention of vibratory massage therapy on forearm grip strength and endurance. 14th International Conference on Humanizing Work and Work Environment (HWWE 2016). Jalandhar. https://www.researchgate.net/publication/311647927_Effect of One_Week_Intervention_of_Vibratory_Massage_Therapy_on_Forearm_Grip_Strength_ and_Endurance

[6] Moras G, Rodriguez S, Tous FJ, Ranz D, Mujika I. A vibratory bar for upper body: Flexibility and acute effects on EMGrms activity. Journal of Strength and Conditioning Research. 2010; 28(8):2132-42. [DOI:10.1519/JSC.0b013e3181aa3684] [PMID]

[7] Hazell TJ, Jakobi JM, Kenno KA. The effects of whole-body vibration on upper- and lower-body EMG during static and dynamic contractions. Applied Physiology Nutrition and Metabolism. 2007; 32(6):1156-63. [DOI:10.1139/H07-116] [PMID]

[8] Bosco C, Cardinale M, Tsarpela O. Influence of vibration on mechanical power and electromyogram activity in human arm flexor muscles. European Journal of Applied Physiology. 1999; 79(4):306-11. [DOI:10.1007/s004210050512] [PMID]

[9] Weerapong P, Hume PA, Kolt GS. The mechanism of massage and effects on performance, muscles recovery and injury prevention. Sports Medicine. 2005; 35(3):235-56. [DOI:10.2165/00007256-200535030-00004] [PMID]

[10] Boyas S, Guevel A. Neuromuscular fatigue in healthy muscle: underlying factors and adaptation mechanisms. Annals of Physical and Rehabilitation Medicine. 2011; 54(2):88-108. [DOI:10.1016/j.rehab.2011.01.001] [PMID]

[11] Merletti R, Parker PJ, Parker PA. Electromyography: Physiology, engineering, and non- invasive appli- cations. New Jersey: John Wiley \& Sons; 2004. https:// books.google.com/books/about/Electromyography. html?id=AlZRAAAAMAAJ\&source=kp_book_description

[12] Merletti R, Knaflitz M, Luca D. Myoelectric manifestations of fatigue in voluntary and electrically elicited contractions. Journal of Applied Physiology. 1990; 69(5):1810-20. [DOI:10.1152/jappl.1990.69.5.1810] [PMID]

[13] Griffin L, Garland SJ, Ivanova T, Gossen ER. Muscle vibration sustains motor unit firing rate during submaximal isometric fatigue in human. Journal of Physiology. 2001; 535(3):92936. [DOI:10.1111/j.1469-7793.2001.00929.x] [PMID] [PMCID]

[14] Lowery MM, O'Malley MJ. Analysis and simulation of changes in EMG amplitude during high level fatiguing contraction. IEEE Transactions on Biomedical Engineering. 2003; 50(9):1052-62. [DOI:10.1109/TBME.2003.816078] [PMID]

[15] Alam M, Khan A, Farooq M. Effects of vibration therapy on neuromuscular efficiency \& features of the emg signal based on endurance test. Journal of Bodywork \& Movement Therapies. 2020; 24(4):325-35. [DOI:10.1016/j.jbmt.2020.06.037] [PMID]

[16] Rogers D, MacIsaac D. EMG based muscle fatigue assessment during dynamic contrations using principal component analysis. Journal of Electromyography and Kinesiology. 2011; 21(5):811-8. [DOI:10.1016/j.jelekin.2011.05.002] [PMID]

[17] Bigland-Ritchie B, Donovan E, Roussos C. Conduction velocity and EMG power spectrum changes in fatigue of sustained maximal efforts. Journal of Applied Physiology: Respiratory, Environmental and Exercise Physiology. 1981; 51(5):1300-5. [DOI:10.1152/jappl.1981.51.5.1300] [PMID]

[18] Phinyomark A, Quaine F, Charbonnier S, Serviere C, Tarpin-Bernard F, Laurillau Y. EMG feature evaluation for improving myoelectric pattern recognition robustness. Expert Systems with Applications. 2013; 40(12):4832-40. [DOI:10.1016/j.eswa.2013.02.023]

[19] Farina D, Merletti R. Comparison of algorithms for estimation of EMG variables during voluntary isometric contractions. Journal of Electromyography and Kinesiology. 2000; 10(5):337-49. [DOI:10.1016/S1050-6411(00)00025-0]

[20] Cifrek M, Medved V, Tonkovic S, Ostojic S. Surface EMG based muscle fatigue evaluation in biomechanics. Clinical Biomechanics. 2009; 24(4):327-40. [DOI:10.1016/j.clinbiomech.2009.01.010] [PMID]

[21] Mohd Mukhtar A, Abid AK, Mohd F. Effects of different vibration therapy protocols on neuromuscular performance. Muscle, Ligaments and Tendons Journal. 2021; 11(1):161-77. [DOI:10.32098/mltj.01.2021.17]

[22] Tankisheva E, Jonkers I, Boonen S, Delecluse C. Transmission of whole-body vibration and its effect on muscle activation. Journal of Strength and Conditioning Research. 2014; 27(9):2533-41. [DOI:10.1519/JSC.0b013e31827f1225] [PMID]

[23] Khan AA, O'Sullivan L, Gallwey TJ. Effects of combined wrist flexion/extension and forearm rotation and two levels of relative force on discomfort. Ergonomics. 2009; 52(10):126575. [DOI:10.1080/00140130903040208] [PMID]

[24] Farooq M, Khan AA. Effects of shoulder rotation combined with elbow flexion on discomfort and EMG activity of ECRB muscle. International Journal of Industrial Ergonomics. 2014; 44(6):882-91. [DOI:10.1016/j.ergon.2013.10.010] 
[25] Alam M, Khan A, Farooq M. Effects of vibratory massage therapy on grip strength, endurance time and forearm muscle performance. Work. 2021; 68(3):619-32. [DOI:10.3233/WOR203397] [PMID]

[26] Roman-liu D, Bartuzi P. The influence of wrist posture on the time and frequency EMG signal measures of forearm muscles. Gait and Posture. 2013; 37(3):340-4. [DOI:10.1016/j. gaitpost.2012.07.027] [PMID]

[27] Mogk J, Keir P. The effects of posture on forearm muscle loading during gripping. Ergonomics. 2003; 46(9):956-75. [DO I:10.1080/0014013031000107595] [PMID]

[28] Carpentier A, Duchateau J, Hainaut K. Motor unit behaviour andcontractile changes during fatigue in the human first dorsal interosseus. Journal of Physiology. 2001; 534(3):903-12. [DOI:10.1111/j.1469-7793.2001.00903.x] [PMID] [PMCID]

[29] Felici F, Quaresima V, Fattorini L, Sbriccol P, Filligoi GC, Ferrari M. Biceps brachii myoelectric and oxygenation changes during static and sinusoidal isometric exercises. Journal of Electromyography and Kinesiology. 2009; 19(2):e1-11. [DOI:10.1016/j.jelekin.2007.07.010] [PMID]

[30] Hunter SK, Critchlow A, Enoka RM. Muscle endurance is greater for old men compared with strength-matched young men. Journal of Applied Physiology. 2005; 99(3):890-89. [DOI:10.1152/japplphysiol.00243.2005] [PMID]

[31] Loren GJ, Shoemaker SD, Burkholder TJ, Jacobson MD, Fride NJ, Lieber RL. Human wrist motors: Biomechanical design and application to tendon transfers. Journal of Biomechanics. 1996; 29(3):331-42. [DOI:10.1016/0021-9290(95)00055-0]

[32] Tanaka TH, Leisman G, Mori H, Nishijo K. The effect of massage on localized lumbar muscle fatigue. BMC Complementary and Alternative Medicine. 2002; 2:9. [DOI:10.1186/14726882-2-9] [PMID] [PMCID]

[33] Gonzalez-Izal M, Malanda A, Navarro-Amezqueta I, Gorostiaga EM, Mallor F, Ibanez J, et al. EMG spectral indices and muscle power fatigue during dynamic contractions. Journal of Electromyography and Kinesiology. 2010; 20(2):233-40. [DOI:10.1016/j.jelekin.2009.03.011] [PMID]

[34] Phinyomark A, Thongpanja S, Hu H, Phukpattaranont P, Limsakul $\mathrm{C}$. The usefulness of mean and median frequencies in electromyography analysis. In: Naik GR, editor. Computational intelligence in electromyography analysis: A perspective on current applications and future challenges. Germany: Books on Demand; 2012. https://books.google.com/ books/about/Computational_Intelligence_in_Electromyo. html?id=_omiDwAAQBAJ\&source=kp_book_description

[35] Viitasalo JH, Komi PV. Signal characteristics of EMG during fatigue. European Journal of Applied Physiology and Occupational Physiology. 1977; 37(2):111-21. [DOI:10.1007/ BF00421697] [PMID] 